\title{
Information hat viele Gesichter
}

TREFFPUNKT :1: 1 (1):

hat viele Gesichter

24. bis 31 . Oktober 2010

In Kooperation mit dem Deutschen Bibliotheksverband e.V und gefördert durch das Bundesministerium für Bildung und Forschung präsentierten sich Bibliotheken in ganz Deutschland vom 24.10. bis 31.10.2010 mit zahlreichen Aktivitäten als Lernorte und Orte der Kommunikation auf vielfältigste Weise. Die Palette der Veranstaltungen reichte von Poetry-Slams, Lesenächten, Autorenlesungen über Ausstellungen und Präsentationen bis hin zu verschiedenen Serviceangeboten wie z.B. Büchertausch. In Sachsen fanden insgesamt 160 Veranstaltungen in den Bibliotheken statt.
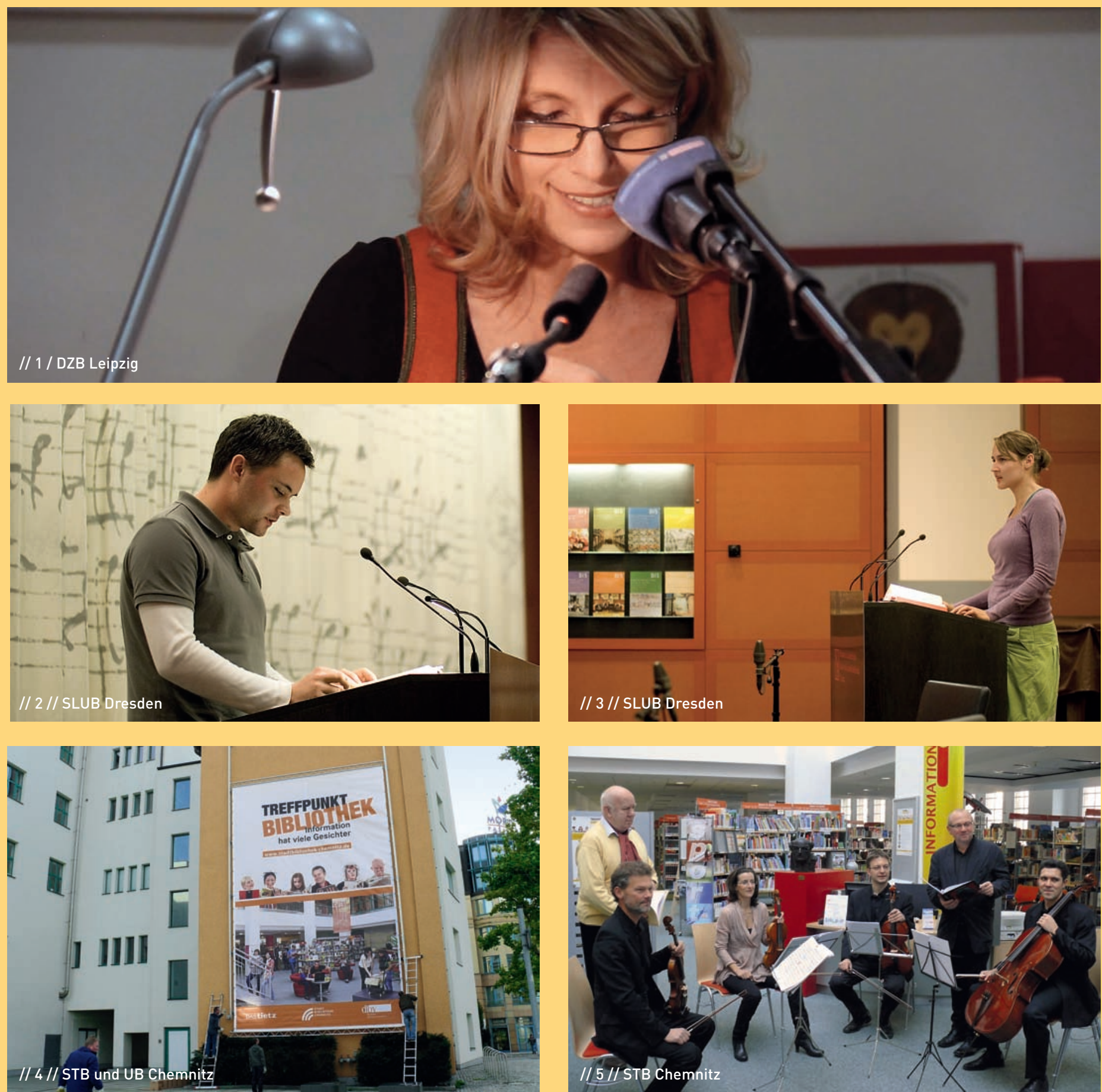

// 1 // Else Buschheuer liest in der DZB Leipzig aus Ihrem Roman „Masserberg“ (Foto: Karsten Sachse, DZB Leipzig). // 2 // 3 // 9 // 10 // In der SLUB Dresden war am 29.10.2010 Eigeninitiative der Mitwirkenden gefragt. Unter dem Motto „Ich lese... mein Lieblingsbuch“ stellten Leserinnen und Leser einen ganzen Abend lang nonstop ihre Lieblingslektüre vor (Fotos: Torsten Lohse). // 4 // Mit einem großen Banner warben die Stadtbibliothek und Universitätsbibliothek Chemnitz gemeinsam für die Aktionswoche „Treffpunkt Bibliothek“. // 5 // Klaus Walther, Andreas Eichler, Rainer Klis und das Streichquartett Locarino eröffneten die Lesewoche in der Stadtbibliothek Chemnitz. 

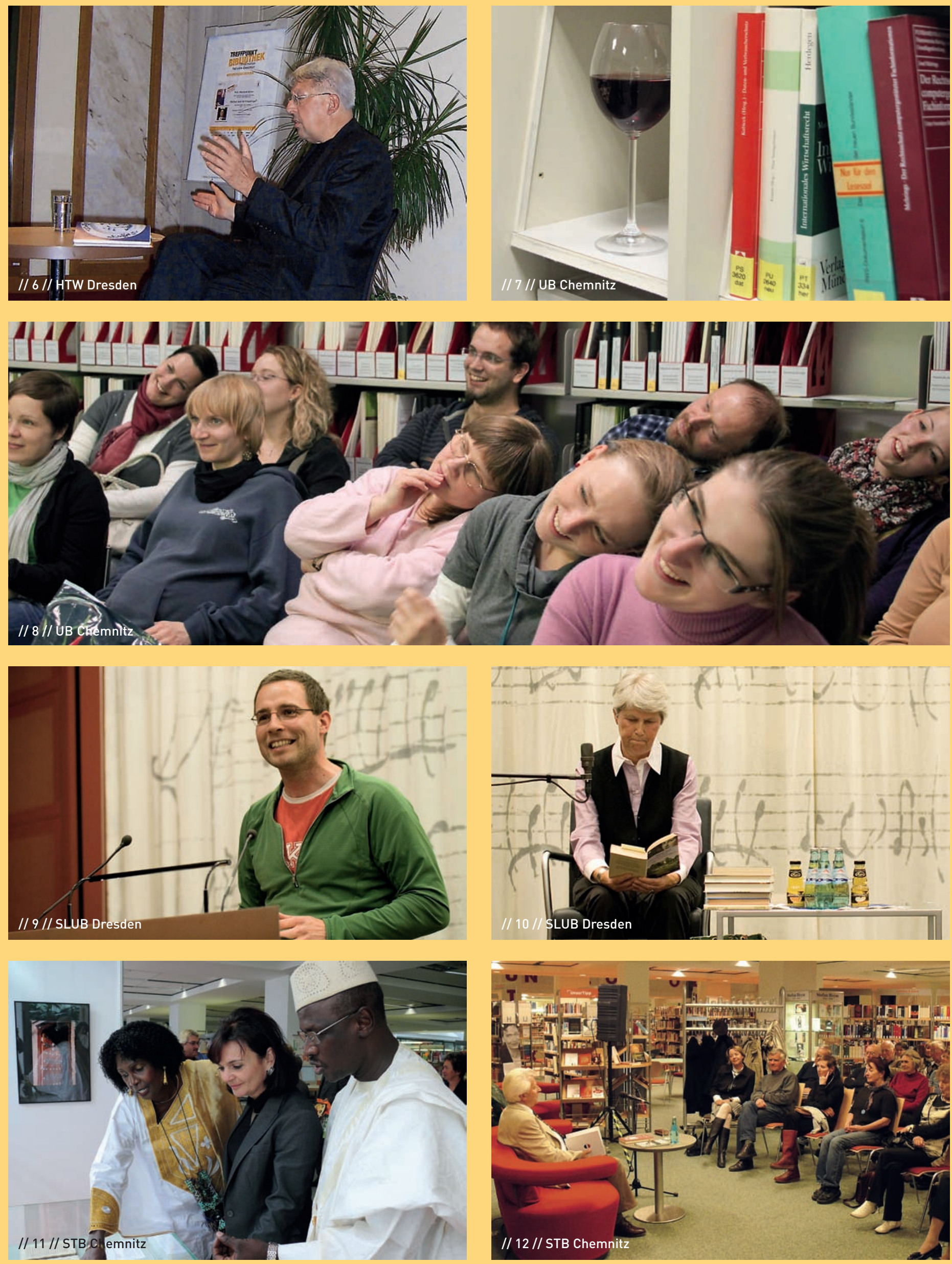

// 6 // Prof. Eberhard Görner stellte in der Bibliothek der HTW Dresden sein neuestes Buch .,Weißes Gold im Erzgebirge?“" vor. // 7 // „Lange Nacht der Bibliothek“" in der UB Chemnitz: Bücher und Wein so soll es sein ... // 8 // BIBO-Klick - Ein großes Bibliothekspuzzle auf Filmleinwand in der UB Chemnitz. // 11 // Ausstellung „Die Handschriften von Timbuktu“ zeigte Originalmanuskripte aus der malischen Partnerstadt in der Stadtbibliothek im TIETZ. Zur Eröffnung begrüßte Direktorin Elke Beer die Botschafterin des westafrikanischen Staates Mali Frau Fatouma Sitè Diakitè. // 12 // Verlegerlegende Elmar Faber stellte in der Stadtbibliothek Chemnitz seinen neuen Essayband vor. 